\title{
Ocean Dynamics and the Nature of Air-Sea Interactions over the North Atlantic at Decadal Time Scales
}

\author{
W. PARK \\ Max Planck Institute for Meteorology, Hamburg, Germany \\ M. LATIF \\ Leibniz Institute of Marine Sciences, Kiel, Germany
}

(Manuscript received 21 May 2004, in final form 13 August 2004)

ABSTRACT

\begin{abstract}
The dependence of the air-sea interactions over the North Atlantic on the ocean dynamics is explored by analyzing multicentury integrations with two different coupled ocean-atmosphere models. One is a coupled general circulation model (CGCM), in which both the atmospheric and the oceanic components are represented by general circulation models (GCMs). The second coupled model employs the same atmospheric GCM, but the oceanic GCM is replaced by a fixed-depth mixed layer model, so that variations of the ocean dynamics are excluded. The coupled model including active ocean dynamics simulates strong multidecadal variability in the sea surface temperature (SST) of the North Atlantic, with a monopolar spatial structure. In contrast, the coupled model that employs an oceanic mixed layer model and thus does not carry active ocean dynamics simulates a tripolar SST anomaly pattern at decadal time scales. The tripolar SST anomaly pattern is characterized by strong horizontal gradients and is by definition the result of the action of surface heat flux anomalies on the oceanic mixed layer.

The differences in the spatial structures of the dominant decadal SST anomaly patterns yield rather different atmospheric responses. While the response to the monopolar SST anomaly pattern is shallow and thermal, the response to the tripolar SST anomaly pattern involves changes in the transient eddy statistics. The latter can be explained by the strong horizontal SST gradients that affect the surface baroclinicity, which in turn affects the growth rate of the transient eddies. The differences in the atmospheric response characteristics yield completely different response patterns. In the coupled run with active ocean dynamics, the sea level pressure (SLP) anomalies exhibit a rather homogeneous pattern that resembles somewhat the East Atlantic Pattern (EAP), while a dipolar (North Atlantic Oscillation) NAO-like SLP anomaly pattern is simulated in the coupled run without active ocean dynamics.
\end{abstract}

\section{Introduction}

The North Atlantic Ocean exhibits variability of its surface climate on a wide range of time scales (e.g., Deser and Blackmon 1993; Kushnir 1994). Bjerknes (1964) hypothesized that the North Atlantic is basically driven by the atmosphere at interannual time scales, while ocean dynamics play a crucial role at decadal to multidecadal time scales. Strong multidecadal variability in the sea surface temperature (SST) of the Atlantic Ocean has been reported and linked to variations in Sahelian rainfall by Folland et al. $(1984,1986)$. Coupled ocean-atmosphere models are capable of producing the multidecadal variability (e.g., Delworth et al. 1993;

Corresponding author address: Dr. M. Latif, Leibniz Institute of Marine Sciences, Kiel University, Düsternbrooker Weg 20, 24105 Kiel, Germany.

E-mail: mlatif@ifm-geomar.de
Timmermann et al. 1998; Delworth and Mann 2000). Although there is disagreement about the specific processes that lead to the multidecadal variability, it is commonly believed that variations in the thermohaline circulation (THC) are important in driving such fluctuations over the North Atlantic (e.g., Delworth et al. 1993; Latif 1998; Latif et al. 2004).

The nature of the air-sea interactions over the North Atlantic, however, is not well understood. Many different hypotheses have been put forward, ranging from the stochastic climate model scenario (Hasselmann 1976; Frankignoul 1985) to fully coupled feedback loops (e.g., Timmermann et al. 1998; Delworth et al. 1997). In particular, it is not even clear whether the atmosphere over the North Atlantic is sensitive at all to extratropical sea surface temperature anomalies. Here, we explore the nature of the air-sea interactions over the North Atlantic by conducting coupled model experiments with and without the inclusion of active ocean dynamics. Similar experiments were described by 
Winton (2003), who used the fixed current approach. Since the presence or absence of active ocean dynamics has a strong influence on the spatial SST anomaly pattern, it is hoped to find important hints on the nature of the air-sea interaction by comparing these two cases. Visbeck et al. (1998) have shown by periodically forced ocean model simulations, in which flux anomalies that go along with variations of the North Atlantic Oscillation (NAO) drive the ocean, that the SST anomaly pattern changes from a tripolar to a more monopolar structure when the frequency of the forcing is decreased. This may have important consequences for the overlying atmosphere, since the tripolar SST anomaly pattern may force a different atmospheric response than the monopolar anomaly pattern.

Two types of atmospheric response have been described in the literature. One is baroclinic, shallow, and thermal, with anomalously low (high) pressure over anomalously warm (cold) SST (Lindzen and Nigam 1987). The other is barotropic and involves changes in the surface baroclinicity and in the statistics of the transient eddies (Palmer and Sun 1985). The latter generally results in anomalously high (low) pressure downstream of a positive (negative) SST anomaly. We address the nature of the atmospheric response by means of two coupled model experiments. It is shown that the inclusion of active ocean dynamics favors the thermal response of Lindzen and Nigam (1987), while its absence favors the eddy-type response of Palmer and Sun (1985).

The paper is organized as follows: We briefly describe in section 2 the coupled models and the performed experiments. The results are presented in section 3. The paper is concluded with a summary and a brief discussion of the results in section 4 .

\section{Coupled models and experiments}

We use here the atmospheric general circulation model (AGCM) ECHAM5 of the Max Planck Institute for Meteorology (MPI) developed and described in detail by Roeckner et al. (2003). The horizontal resolution of ECHAM5 is T42 $\left(2.8^{\circ} \times 2.8^{\circ}\right)$, and it is run with 19 vertical levels. ECHAM5 was coupled to two different ocean models. One coupled model employs the MPIOM1, which is an ocean general circulation model (OGCM) developed by MPI. The model described in detail by Marsland et al. (2003) is based on the primitive equations, makes use of the Boussinesq and hydrostatic approximations, and contains an embedded dynamical/thermodynamical sea ice model. The OGCM MPI-OM1 has a variable horizontal resolution, with relatively high resolution in the high latitudes and near the equator $(\sim 10-50 \mathrm{~km})$. The coupled model employing MPI-OM1 (ECHAM5-OGCM), which is integrated without flux adjustments, simulates pronounced multidecadal variability in the North Atlantic (Latif et al.
2004). However, the simulated North Atlantic multidecadal variability is almost twice as strong as that observed during the period 1870-1998. The coupled general circulation model (CGCM) was used also by Pohlmann et al. (2004) to study the model's decadal predictability potential. The second coupled model replaces the OGCM by a fixed-depth $(50 \mathrm{~m})$ mixed layer ocean (MLO) and a thermodynamic sea ice module, so that by definition, no active ocean dynamics is considered. This coupled model (ECHAM5-MLO) is a realization of Hasselmann's (1976) simplest stochastic climate model, in which SST variability can be produced only by the integration of surface heat anomalies. There may be, however, a feedback of the ocean's SST to the atmosphere, as described below. The sea surface temperature variability in midlatitudes simulated by such a simplified coupled model was discussed, for instance, by Dommenget and Latif (2002).

Both coupled models were integrated for $500 \mathrm{yr}$. Daily, monthly, and annual data are available for analysis. The model outputs thus allow the investigation of mean and eddy quantities in the atmosphere. To compare the two coupled runs performed with and without active ocean dynamics, we compute decadal standard deviations and perform correlation, empirical orthogonal function (EOF), and linear regression analyses.

\section{Results}

Our focus in this paper is on decadal time scales. We start the analysis of the coupled runs by computing the standard deviations of 10-yr mean surface temperature and sea level pressure. Since both runs have a duration of $500 \mathrm{yr}$, stable estimates of the decadal standard deviations can be obtained. The ratios of the standard deviations (ECHAM5-OGCM/ECHAM5-MLO) are shown in Fig. 1. Decadal surface temperature variability is enhanced by the presence of active ocean dynamics over the North Atlantic/European region, over parts of the tropical and North Pacific, and over parts of the Southern Ocean (Fig. 1a). These were the regions highlighted by Pohlmann et al. (2004) for having high decadal predictability potential. The corresponding figure for SLP shows rather limited similarity to the surface temperature pattern (Fig. 1b). However, we do find enhanced decadal variability over the North Atlantic. The decadal standard deviation ratios, however, are much smaller compared to those for surface temperature. Over the North Atlantic, for instance, the presence of active ocean dynamics increases the standard deviation of decadal means only by about $20 \%$. This result, which was also obtained by other modeling groups (e.g., Manabe and Stouffer 1996), has often been used to argue that the impact of changes in ocean currents on the atmosphere is relatively small. We show that this is not the case-although the level of the decadal variability is not strongly influenced by the pres- 
a) decadal stddev ratio ECHAM5-OGCM/ECHAM5-MLO, sfc temp.

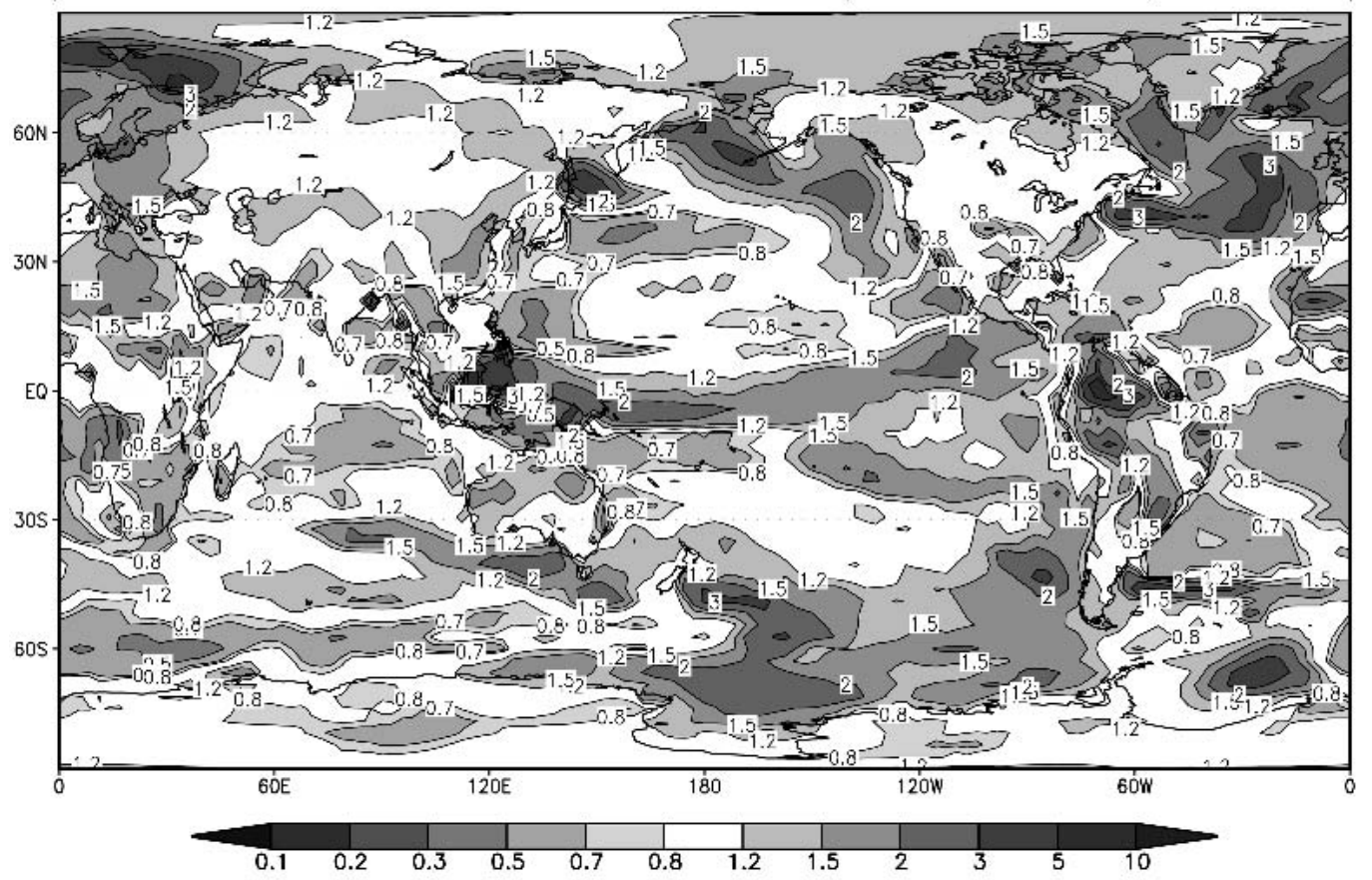

b) decadal stddev ratio ECHAM5-OGCM/ECHAM5-MLO, SLP

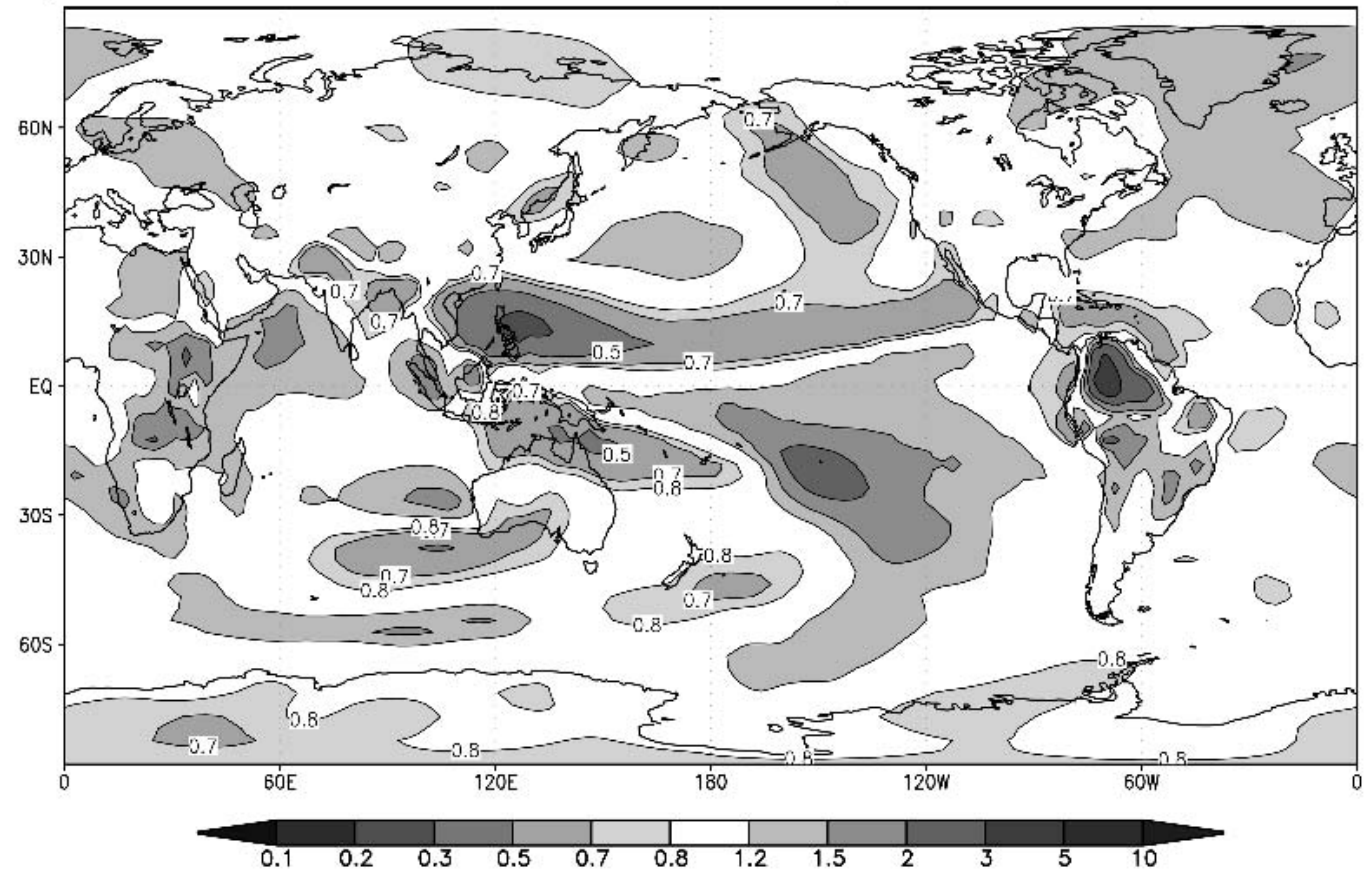

FIG. 1. Ratio of decadal standard deviations (based on 10-yr means) between the coupled run with the dynamical ocean model (ECHAM5-OGCM) and that with the mixed layer ocean model (ECHAM5-MLO): (a) Surface temperature and (b) SLP.

ence of active ocean dynamics, the structure of both the air-sea interactions and the atmospheric response is strongly affected. We concentrate in the following on the North Atlantic region.
Next, we computed an index of North Atlantic SST, which is defined as the area average over the region $40^{\circ}-60^{\circ} \mathrm{N}, 50^{\circ}-10^{\circ} \mathrm{W}$. This index was proposed by Latif et al. (2004) to monitor changes in the North Atlantic 


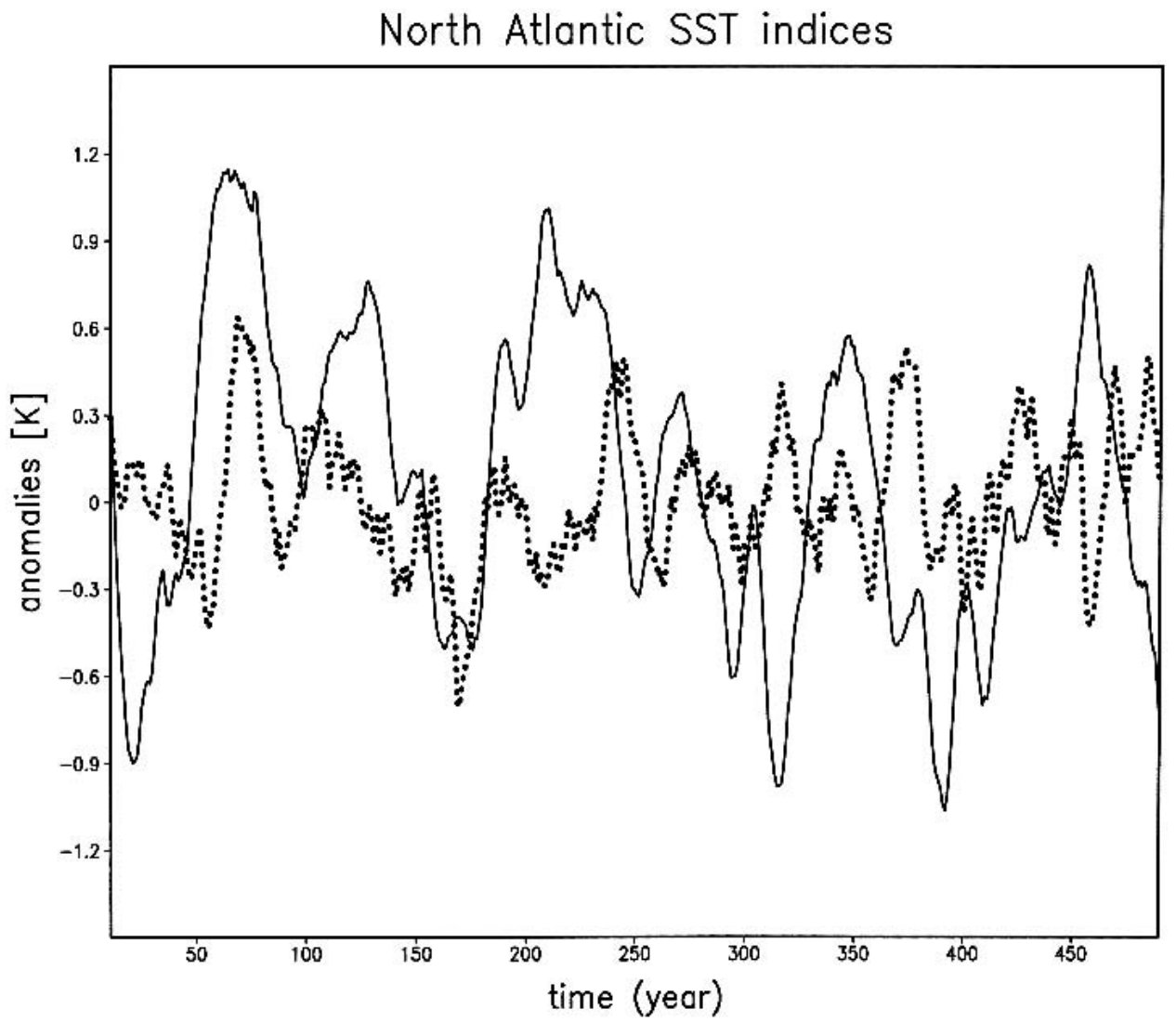

FIG. 2. Time series of North Atlantic SST averaged over the region $40^{\circ}-60^{\circ} \mathrm{N}, 50^{\circ}-10^{\circ} \mathrm{W}$ in the two coupled runs. The time series were smoothed by applying an 11-yr running mean.

THC. We contrast the North Atlantic SST indices obtained from the two coupled models in Fig. 2. To highlight the multidecadal variability, both time series were low-pass filtered by applying an 11-yr running mean filter. The multidecadal North Atlantic SST variability is, as expected from Fig. 1, much stronger in the coupled run with active ocean dynamics (ECHAM5OGCM) compared to that without (ECHAM5-MLO). To derive the spatial structures associated with the decadal SST variability, correlation maps for SST and SLP were computed by using the two North Atlantic SST indices as reference time series. The correlations are based on values to which an 11-yr running mean filter was applied.

The characteristic decadal-scale SST anomaly pattern simulated in the run with active ocean dynamics (ECHAM5-OGCM) is rather flat, with positive SST anomalies over most of the North Atlantic (Fig. 3a). An anticorrelation exists in the South Atlantic (not shown). The SST anomaly pattern in the run with active ocean dynamics is consistent with that obtained from observations and mainly forced by variations of the THC in the CGCM, as described by Latif et al. (2004). The corresponding atmospheric SLP correlation pattern is also rather flat (Fig. 4a), with anomalously low SLP over anomalously warm SST. This SLP pattern resembling the East Atlantic Pattern (EAP; Wallace and Gutzler 1981) is also found by standard EOF analysis. The EOF analysis was performed using the last $400 \mathrm{yr}$ of the integration. The leading EOF mode of low-passfiltered (applying an 11-yr running mean filter) SLP anomalies over the North Atlantic accounting for about $43 \%$ of the variance resembles the NAO, while the second most energetic EOF mode explaining about $17 \%$ of the variance resembles the EAP (Figs. 5a and $5 c)$. Only the principal component of the latter is correlated in a statistically significant manner $(r \sim 0.6)$ with a North Atlantic THC index, the meridional overturning at $30^{\circ} \mathrm{N}$.

The EOF analysis applied to the low-pass-filtered SLP anomalies simulated by ECHAM5-MLO (again using the last $400 \mathrm{yr}$ ) yields the same leading mode, the NAO, but a different second mode (Figs. 5b and 5d). The differences between the two second-most energetic EOF modes are most pronounced over Europe. While in the run with active ocean dynamics the main SLP anomaly extends well into Europe, an anomaly of opposite sign to that over the eastern Atlantic is simulated 
a) corr. of SfC temp. with decadal NA SST, ECHAM5-OGCM

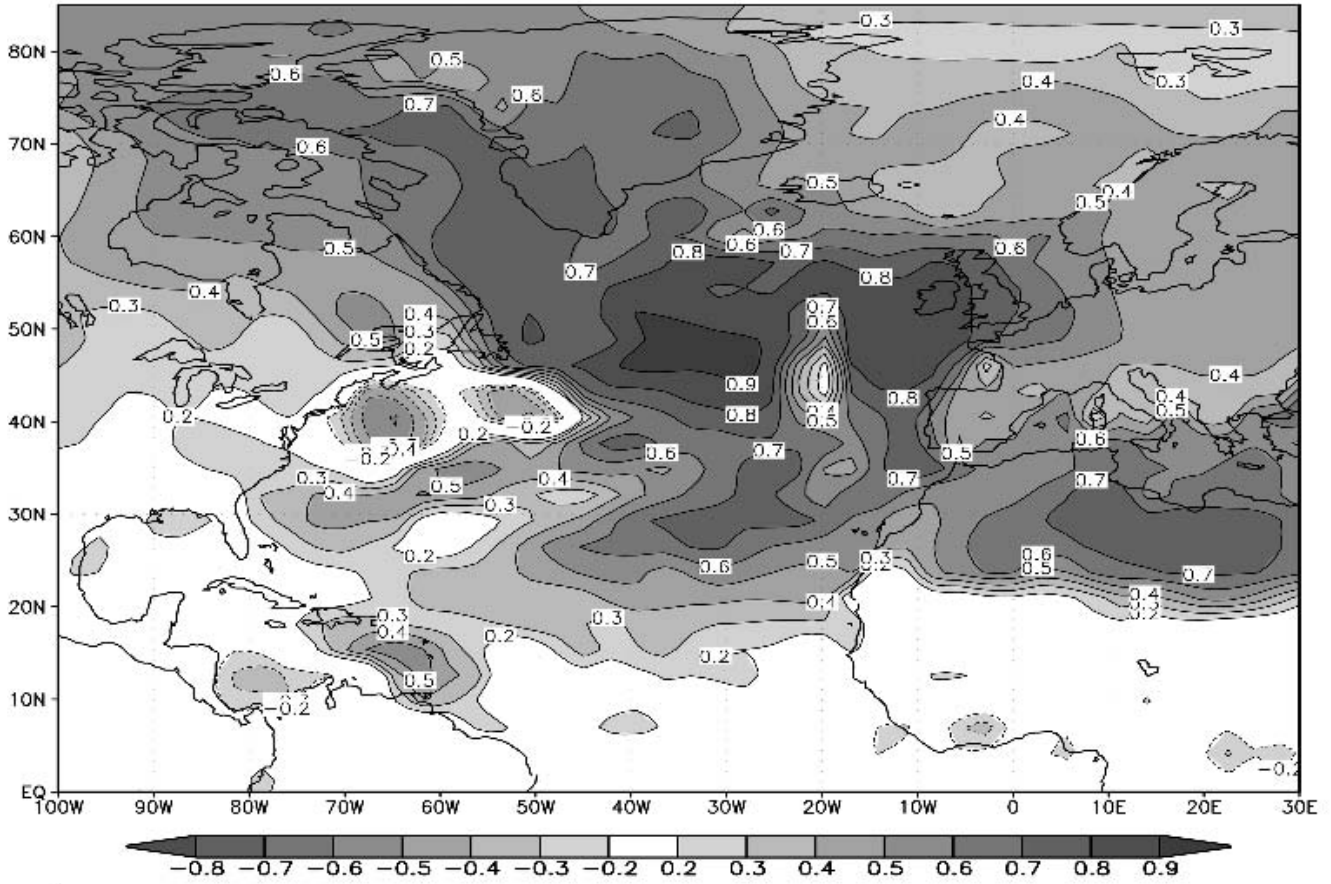

b) corr. of sfc temp. with decadal NA SST, ECHAM5-MLO

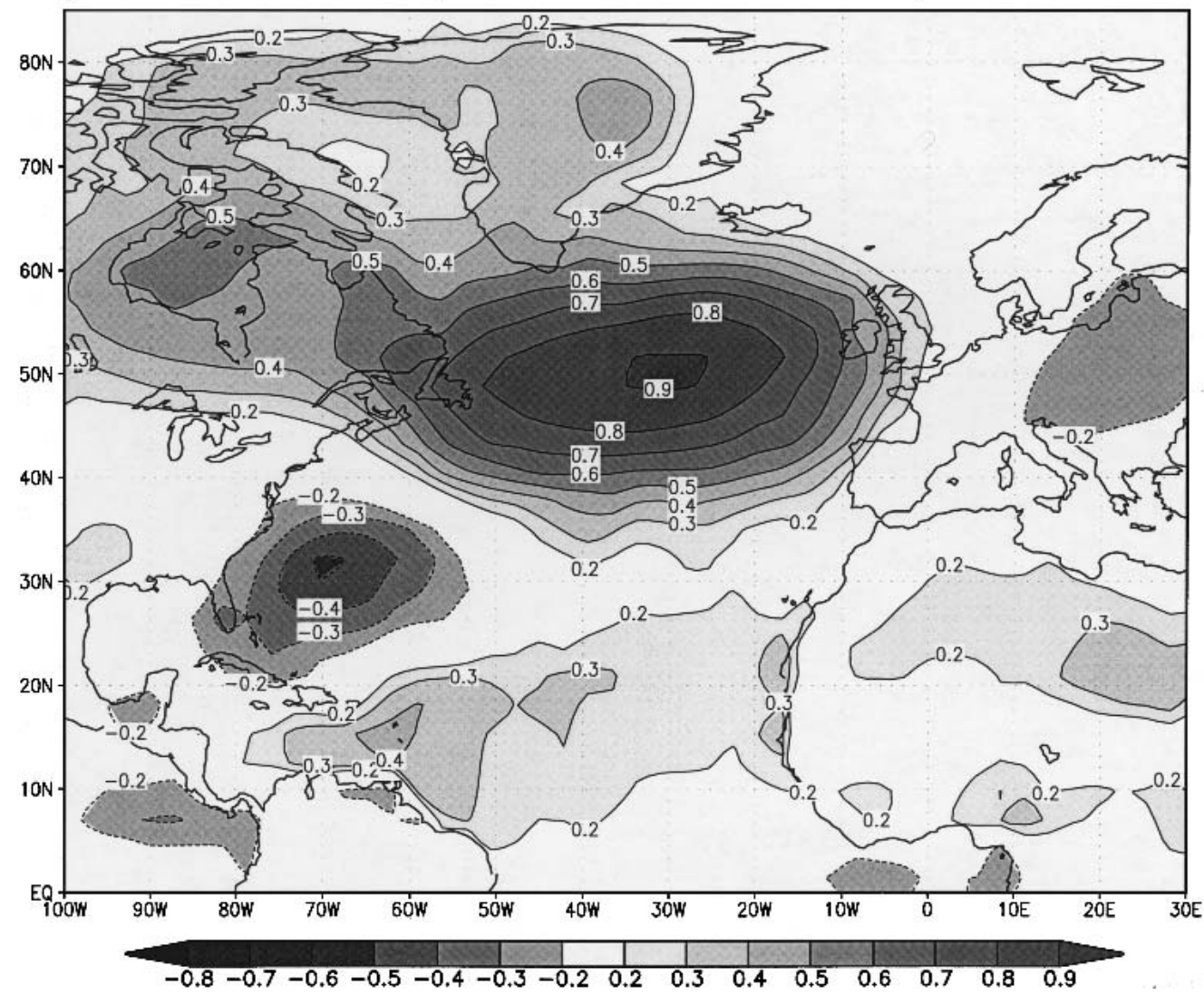

FIG. 3. Maps of correlation coefficients of surface temperature with the North Atlantic SST index: (a) in the coupled run with the dynamical ocean model (ECHAM5-OGCM) and (b) in the coupled run with the mixed layer model (ECHAM5-MLO). An 11-yr running mean filter was applied to both variables prior to the analysis. 
a) corr. of SLP with decadal NA SST, ECHAM5-OGCM

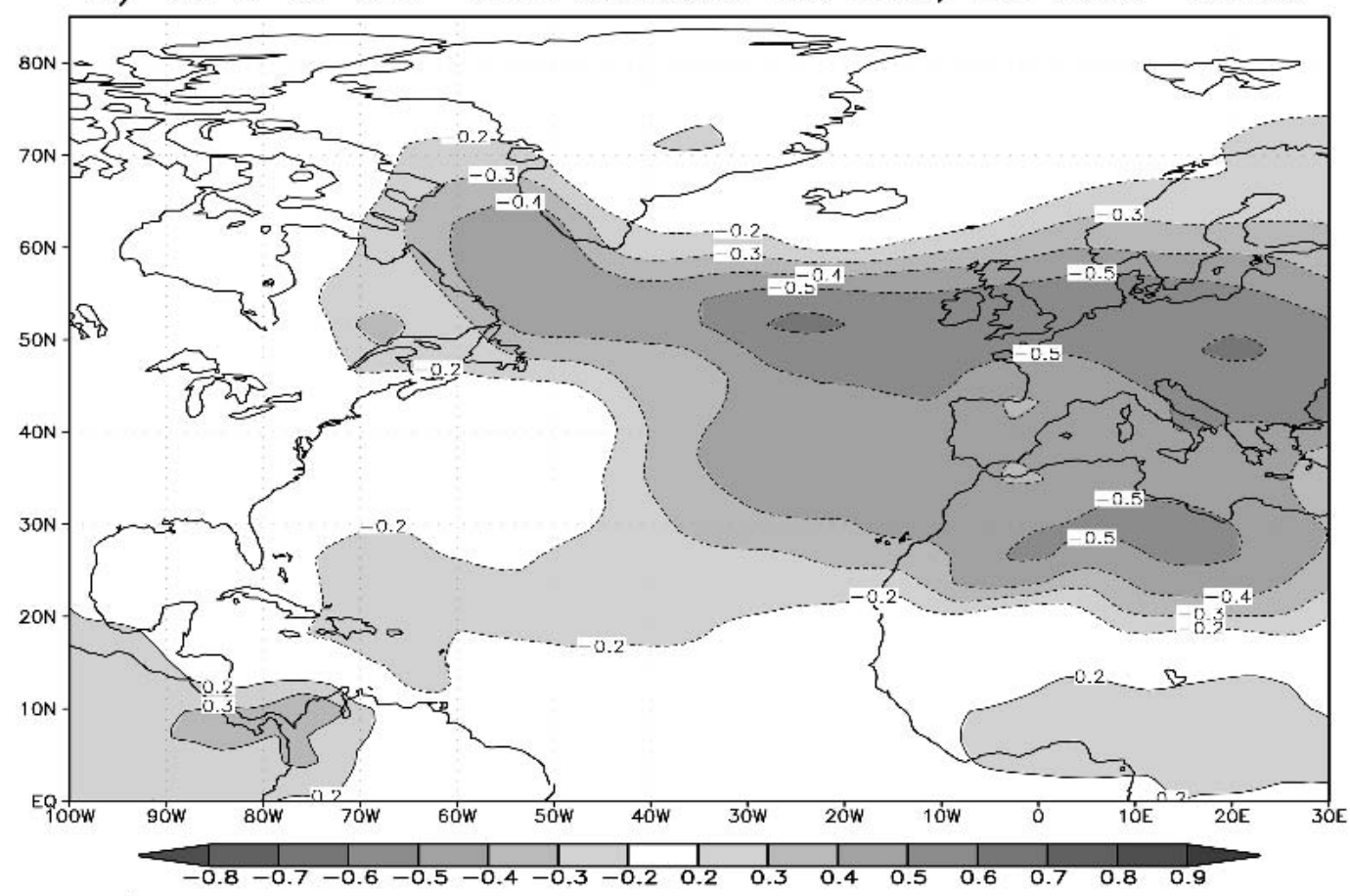

b) corr. of SLP with decadal NA SST, ECHAM5-MLO

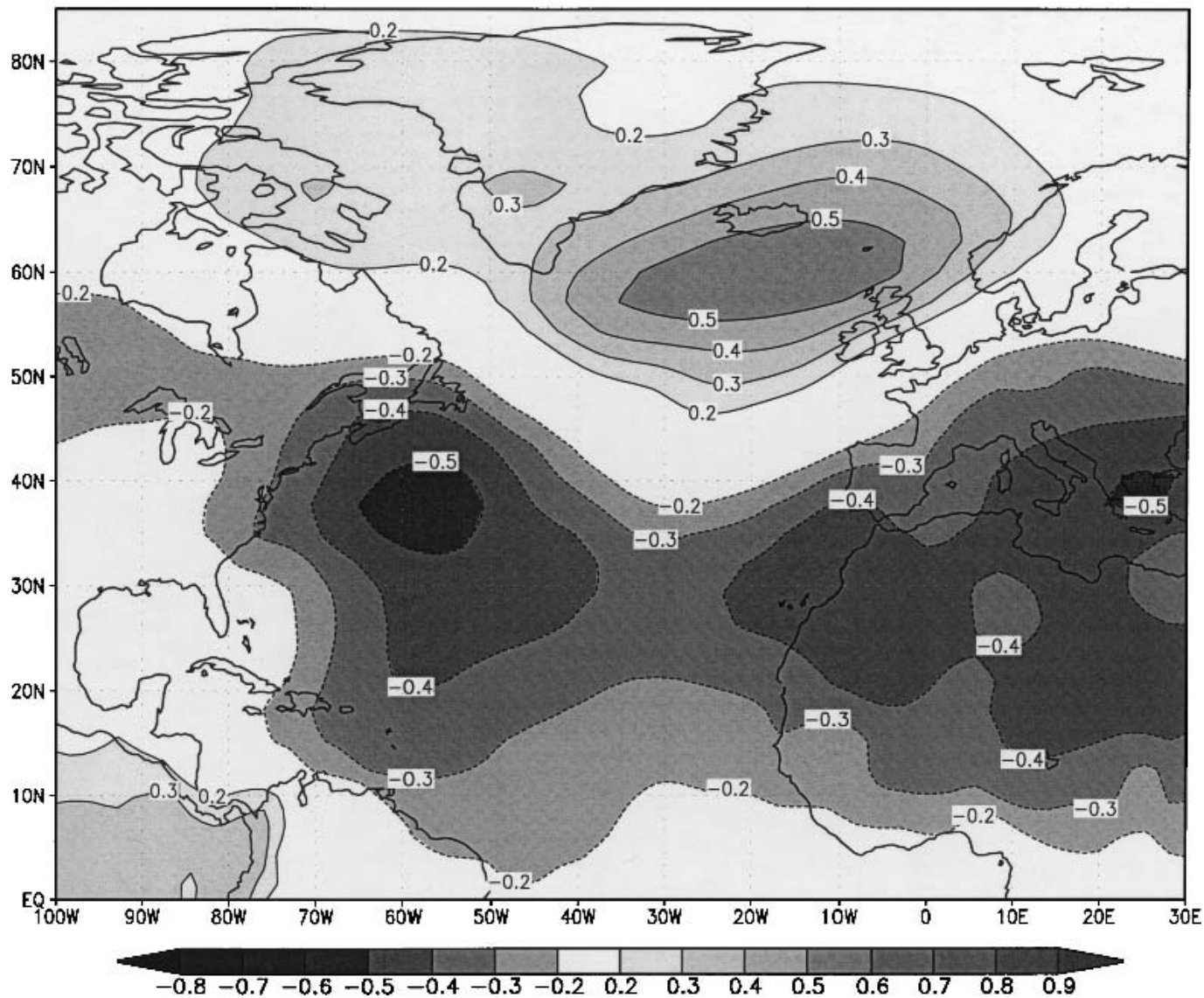

FIG. 4. Same as in Fig. 3, but for SLP. 
a) SLP decadal EOF1 $43 \%$, ECHAM5-OGCM

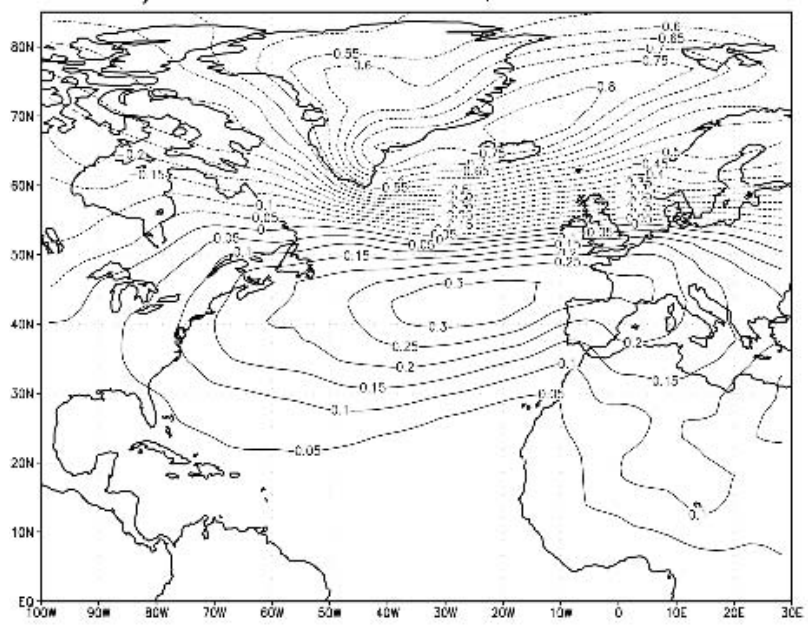

c) SLP decadal EOF2 $17 \%$, ECHAM5-OGCM

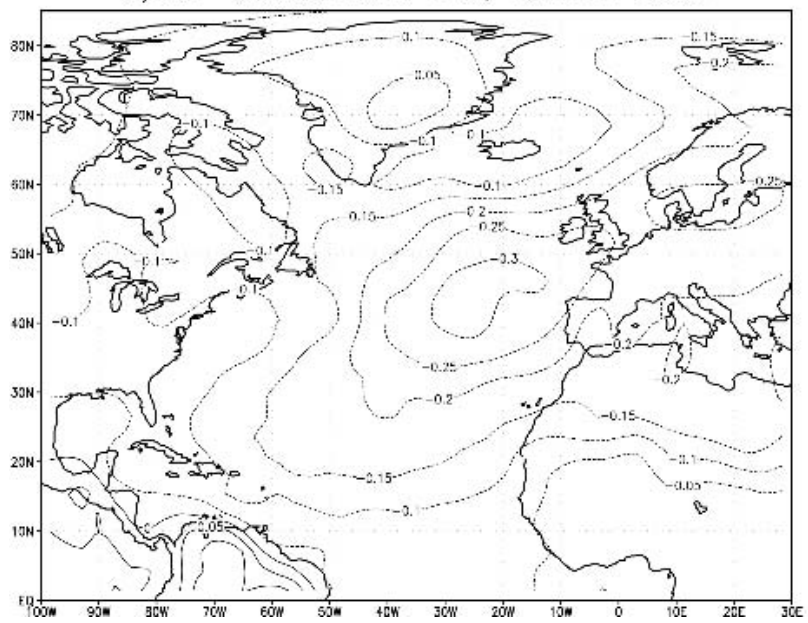

b) SLP decadal EOF1 35\%, ECHAM5-MLO

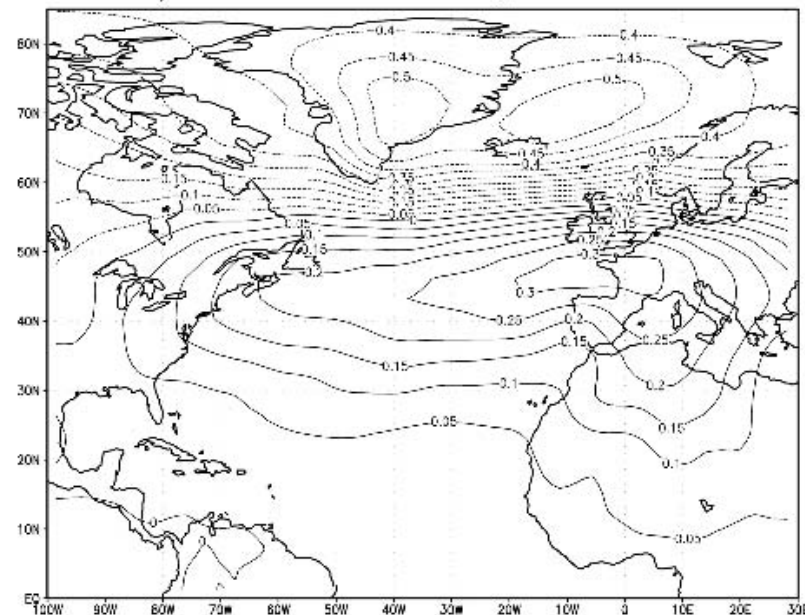

d) SLP decadal EOF2 15\%, ECHAM5-MLO

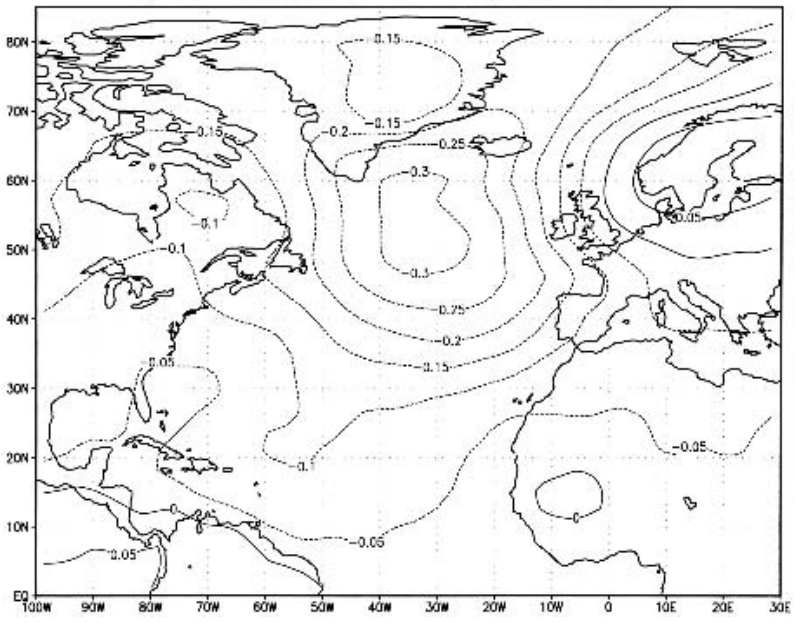

FIG. 5. The two leading EOF modes of low-pass-filtered SLP (applying an 11-yr running mean filter) in the coupled run with active ocean dynamics (ECHAM5-OGCM) and in the coupled run with the mixed layer model (ECHAM5-MLO): (a) EOF1 in ECHAM5OGCM, (b) EOF1 in ECHAM5-MLO, (c) EOF2 in ECHAM5-OGCM, and (d) EOF2 in ECHAM5-MLO.

in ECHAM5-MLO. Furthermore, the main SLP anomaly covers a much larger region of the Atlantic in ECHAM5-OGCM relative to ECHAM5-MLO. Thus, the modal structure of the decadal SLP variability over the North Atlantic is changed by the presence of active ocean dynamics.

Next, we computed the number of spatial degrees of freedom from the eigenvalues obtained by the two EOF analyses, as proposed by Bretherton et al. (1999). While in ECHAM5-OGCM the number of spatial degrees of freedom amounts to about 4, the corresponding number derived from ECHAM5-MLO amounts to about 6. Apparently, the presence of active ocean dynamics favors fewer atmospheric variability patterns. This indicates a rather strong influence of the North Atlantic SST on the atmosphere through the presence of active ocean dynamics, which may increase the dec- adal predictability of the atmosphere over the North Atlantic. Overall, these results somewhat support the nonlinear paradigm put forward by Palmer (1993a,b) that the effect of anomalous SST on the atmosphere will be felt by a change in the frequency distribution of the occurrence of certain weather regimes.

Our findings in ECHAM5-OGCM (anomalously low SLP over anomalously warm SST) suggest that the atmospheric response is similar to the one proposed by Lindzen and Nigam (1987). The same relationship between multidecadal changes of SST and SLP was described from observations by Kushnir (1994). From simple physical considerations, one would expect this type of thermal response. To be specific, we note that the SST anomaly pattern (Fig. 3a) is rather flat without any strong large-scale horizontal gradients. Consequently, the surface baroclinicity is not greatly changed 


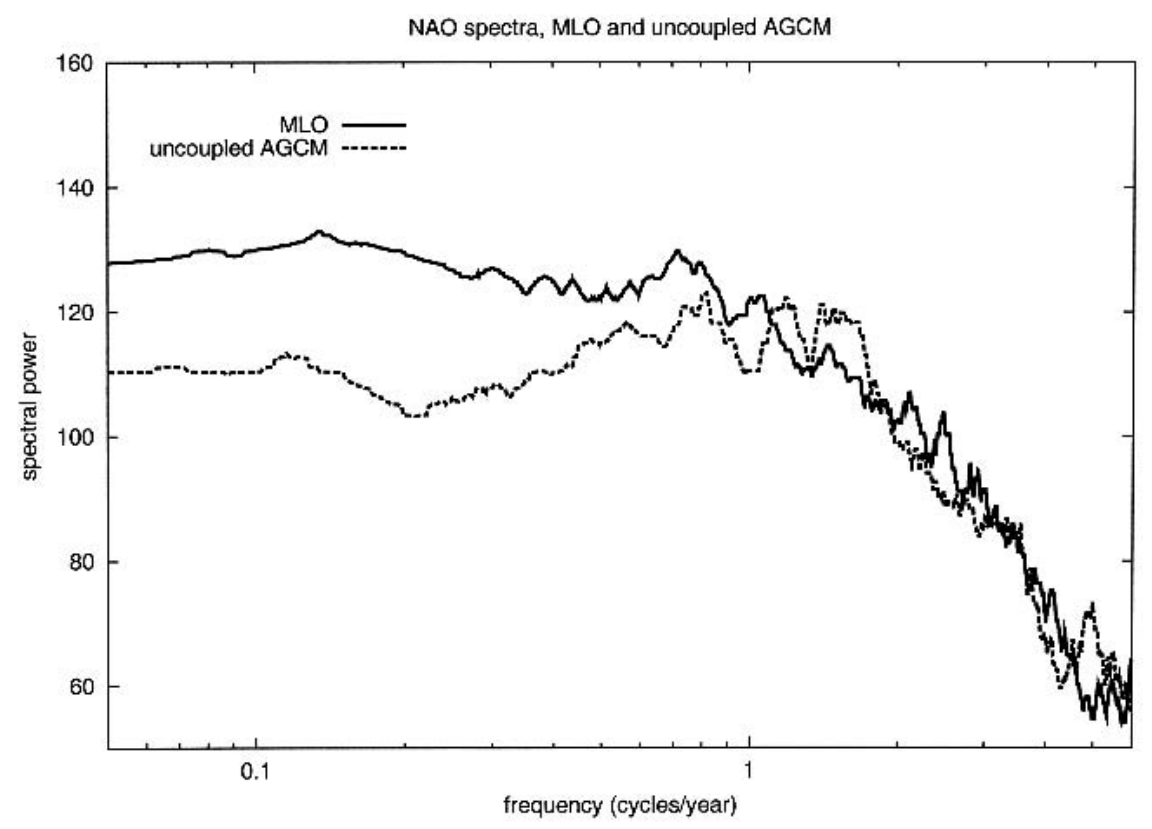

FIG. 6. Frequency spectra (cpy) of the NAO indices in the uncoupled run with ECHAM5 and in ECHAM5-MLO. The spectral analysis is based on monthly data.

by the SST anomaly pattern, so that a change in the statistics of the transient eddies and a subsequent change in the storm track are not to be expected.

The situation changes completely when the coupled run without active ocean dynamics (ECHAM5-MLO) is analyzed, in which the dynamical ocean model was replaced by a mixed layer model. The dominant SST anomaly pattern is the well-known "North Atlantic tripole" (Fig. 3b). It is forced by surface heat flux anomalies associated with the NAO, the leading mode of the atmosphere over the North Atlantic. The NAO-forced SST anomaly (tripole) pattern is characterized by strong horizontal gradients. These may well influence the surface baroclinicity and thus the transient eddy statistics, as hypothesized by Palmer and Sun (1985). This is supported by the associated SLP anomaly correlation pattern, which shows a dipolar structure, with anomalously high pressure downstream of the main positive SST anomaly (Fig. 4b). Overall, the SLP anomaly pattern simulated in the coupled run with the mixed layer model (ECHAM5-MLO) resembles the NAO. Thus, the spatial variability characteristics at decadal time scales are completely different in the two coupled runs. In the run with active ocean dynamics, the main SLP pattern associated with decadal-scale North Atlantic SST changes resembles the East Atlantic Pattern, while, in the run without active ocean dynamics, the main pattern is the North Atlantic Oscillation. Furthermore, we find that the response in ECHAM5-MLO is barotropic in the vertical and baroclinic in ECHAM5-OGCM (not shown).
The comparison of the two coupled runs indicates that the atmosphere over the North Atlantic is sensitive to the underlying SST changes, at least in ECHAM5OGCM. It remains to be shown, however, that the pattern simulated by ECHAM5-MLO shown in Figs. 4b and $5 \mathrm{~b}$ is also a response pattern. Since this pattern is the NAO, it is difficult to separate the internal atmospheric variability from the boundary-forced variability. A multicentury uncoupled run with ECHAM5 forced by seasonally varying climatological SSTs and sea ice extents that would enable us to quantify in detail the boundary-forced component of the atmospheric variability is not available. However, a short uncoupled run of 130-yr duration was performed. We computed spectra of the NAO index from this uncoupled run and from ECHAM5-MLO and show them in Fig. 6. The power is considerably increased in ECHAM5-MLO relative to the uncoupled run at interannual to decadal time scales, clearly indicating an oceanic influence on the NAO.

Also available for analysis were simulations with the ECHAM3 model, a predecessor of ECHAM5, run at the coarser T21 resolution (Dommenget and Latif 2002). The results of a multicentury coupled integration with a fixed-depth $(50 \mathrm{~m})$ mixed layer ocean (similar to ECHAM5-MLO) and an uncoupled run with prescribed climatological SSTs indicate that the decadal variability of the NAO is indeed increased by the presence of the SST variability. Thus, the NAO is not only a forcing pattern that drives the ocean, but also the main response pattern in ECHAM5-MLO, as indicated 
by our correlation and spectral analyses (Figs. 4b and 6).

To get further insight into the dynamics of the two different atmospheric responses, we investigated the "Eady growth rate" $\sigma_{\beta \mathrm{I}}$, a measure of the baroclinity:

$$
\sigma_{\mathrm{BI}}=0.31 f|d \mathbf{v} / d z| / N .
$$

The Eady growth rate depends on the vertical wind sheer $d \mathbf{v} / d z$, the Brunt-Väisälä or bouyancy frequency $N$, and the Coriolis parameter $f$. The Eady growth rate was evaluated at the $850-\mathrm{hPa}$ level. We also investigated some transient eddy statistics, the standard deviation of the bandpass-filtered (2.5-6 days) geopotential height fluctuations, and the associated meridional eddy heat flux. These were analyzed at the $500-\mathrm{hPa}$ level. We compared the two coupled runs by computing regression patterns using the two North Atlantic SST indices (Fig. 2) as reference time series. We show the maps of linear regression coefficients of the selected quantities for both runs in Figs. 7, 8, and 9. Since we consider regressions rather than correlations, the magnitudes of the quantities can be directly compared to each other. All eddy statistics are computed for the winter season [December-February (DJF)]. We also computed decadal differences of the eddy quantities by choosing specific decades of anomalously high and low North Atlantic SSTs. These results, however, are entirely consistent with the regression analyses and therefore are not shown here.

Strong Eady growth rate changes are associated with the decadal North Atlantic SST variations only in the run in which the atmosphere model was coupled to an ocean mixed layer model (ECHAM5-MLO; Fig. 7b). A rather strong decrease of the Eady growth rate is simulated in the region $40^{\circ}-60^{\circ} \mathrm{N}$ over eastern North America that extends in an east-northeastern direction across the Atlantic into northern Europe. Anomalously high Eady growth rates are simulated to the south of this region and north of the main negative anomaly. No strong changes of the Eady growth rate are associated with the decadal North Atlantic SST variations in the coupled run with the dynamical ocean model (ECHAM5-OGCM; Fig. 7a). Thus, the low-level baroclinicity changes associated with the anomalous North Atlantic SST only occur when no active ocean dynamics is considered. This is consistent with the dominant decadal SST anomaly pattern (tripole) in the mixed layer run (ECHAM5-MLO; Fig. 3b). The tripole pattern is characterized by strong horizontal gradients that are likely to influence the low-level baroclinicity.

Consequently, we find strong changes in the statistics of the transient eddies in association with decadal North Atlantic SST variability only in the run without active ocean dynamics (ECHAM5-MLO). Both the standard deviation of the bandpass-filtered $500-\mathrm{hPa}$ height fluctuations (Fig. 8b) and the meridional eddy heat flux (Fig. 9b) change over large parts of the North Atlantic between phases of anomalously high and low
SST. The chain of events is broadly consistent with the barotropic response described by Palmer and Sun (1985). Although we have not analyzed the response simulated in the mixed layer run in more detail, we hypothesize that the transient eddies take a more southward route, so that both the Icelandic low and Azorian high are weakened. This results in an anomalously weak state of the North Atlantic Oscillation (Fig. 4b) when the SSTA tripole is in its positive phase (Fig. 3b).

Only weak changes in the eddy statistics are associated with decadal North Atlantic SST changes in the coupled run with active ocean dynamics (ECHAM5OGCM; Figs. 8a and 9a). This supports the notion of a shallow and thermal atmospheric response, when the variations in the SST are driven by ocean dynamics, specifically by variations in the THC. These force a rather uniform SST anomaly pattern (Fig. 3a) that does not affect the low-level baroclinicity.

\section{Summary and discussion}

We have explored the nature of the air-sea interactions over the North Atlantic at decadal time scales by means of two extended-range coupled model integrations. The two coupled integrations differ in that only one coupled model carries active ocean dynamics. We find that the presence of active ocean dynamics changes the modal structure of the atmospheric variability at decadal time scales. Ocean dynamics drive a rather flat dominant decadal-scale SST anomaly pattern that forces a shallow and thermal atmospheric response resembling the East Atlantic Pattern (EAP). In contrast, the absence of active ocean dynamics leads to a dominant decadal SST anomaly pattern that is tripolar, and this drives a barotropic eddy-type response in the atmosphere that resembles the North Atlantic Oscillation (NAO). The differences in the atmospheric response characteristics are explained by the differences in lowlevel baroclinicity which is strongly altered by anomalous SST only in the run without active ocean dynamics.

We note one important caveat. It has not really been shown in this study that the atmospheric patterns described above (Fig. 4) are really response patterns, that is, that they are forced by the SST changes. This can be shown only by additional uncoupled atmosphere model integrations, in which the two characteristic SST anomaly patterns (Fig. 3) are used to drive the AGCM. Although such uncoupled simulations were not conducted, it has been shown that the nature of the air-sea interactions over the North Atlantic changes considerably depending on whether or not active ocean dynamics are included in the coupled model integrations. The dominant decadal SST anomaly patterns in the North Atlantic are accompanied by completely different atmospheric patterns in the two coupled integrations. This result can be explained, on the one hand, if the 
a) regr. coeff., Eady growth rate, ECHAM5-OGCM $(3 * 10 \mathrm{E}-3)$

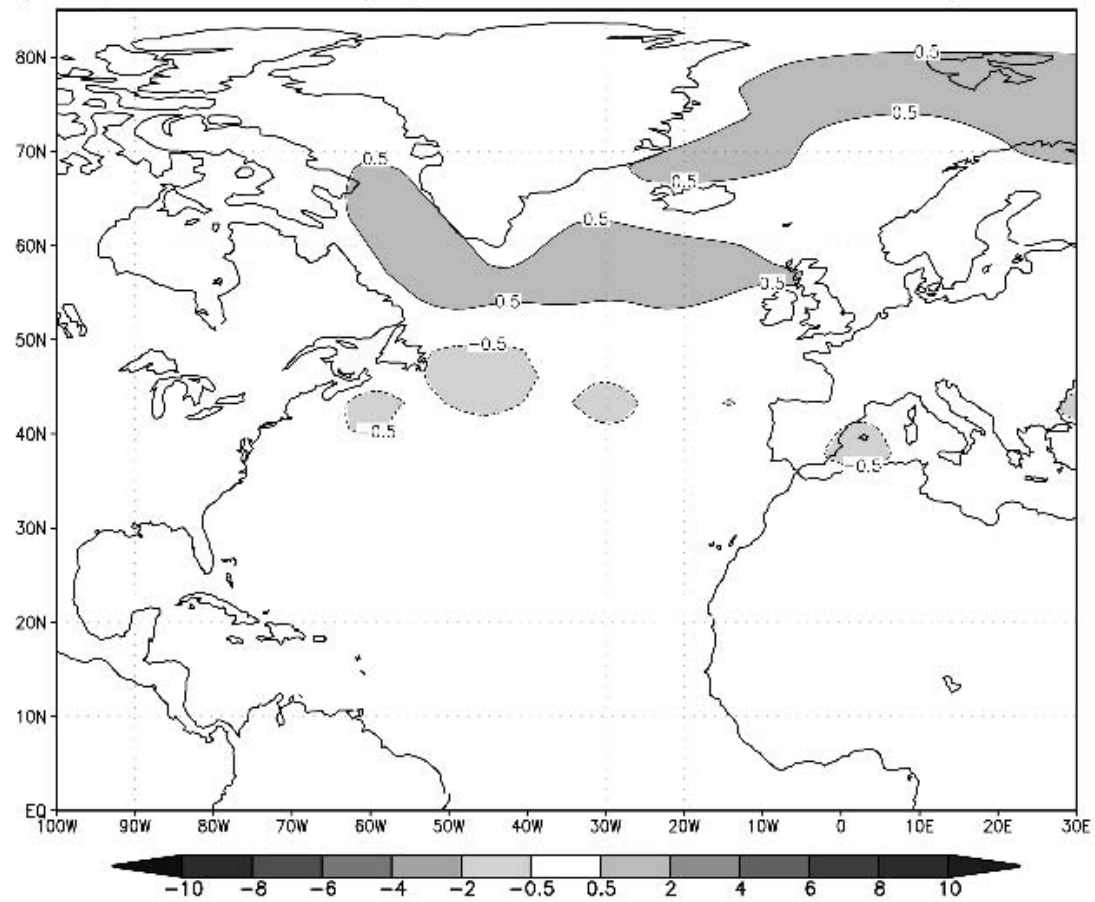

b) regr. coeff., Eady growth rate, ECHAM5-MLO $(3 * 10 \mathrm{E}-3)$

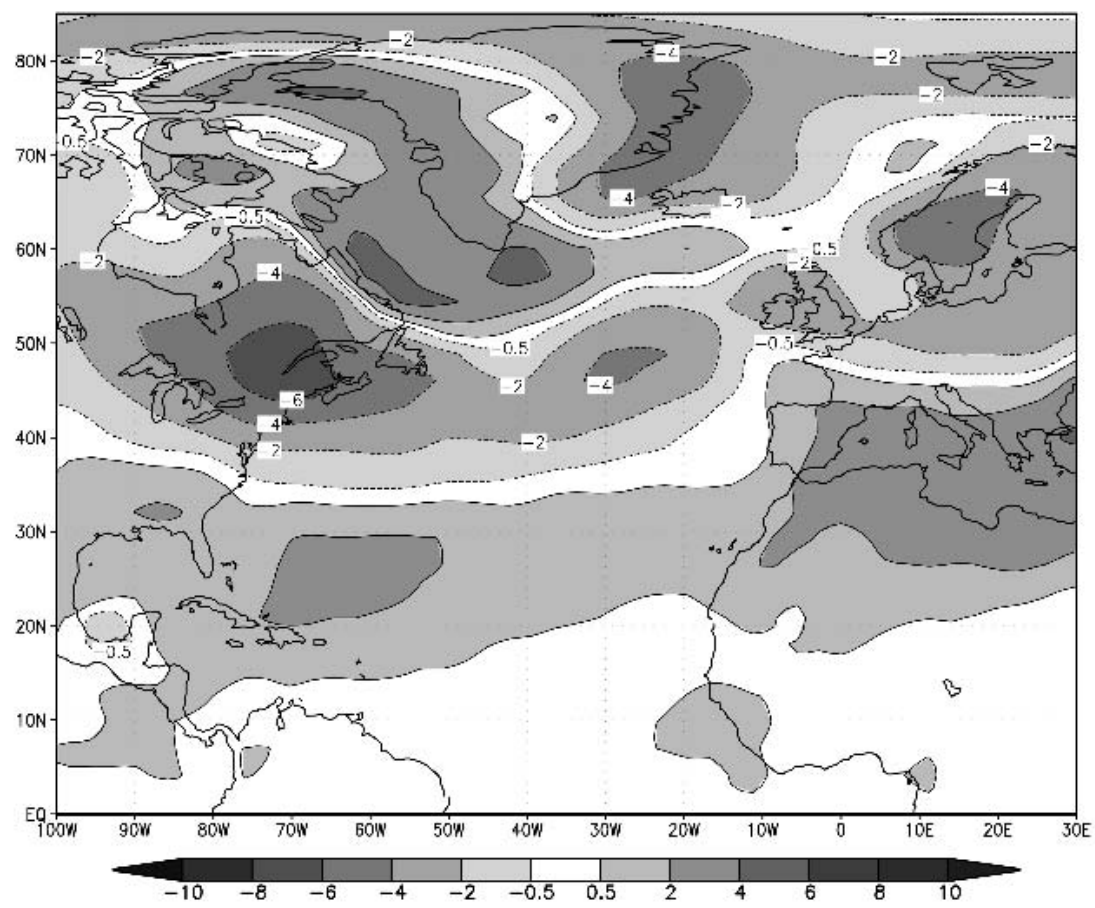

FIG. 7. Maps of linear regression coefficients of the winter (DJF) Eady growth rate at the 850-hPa level with respect to the SST indices shown in Fig. 2: (a) in the coupled run with the dynamical ocean model (ECHAM5-OGCM) and (b) in the coupled run with the mixed layer model (ECHAM5-MLO). An 11-yr running mean filter was applied to both variables prior to the analysis. 
a) regr. coeff., stddev 500hPa GPH, ECHAM5-OGCM (10E-1)

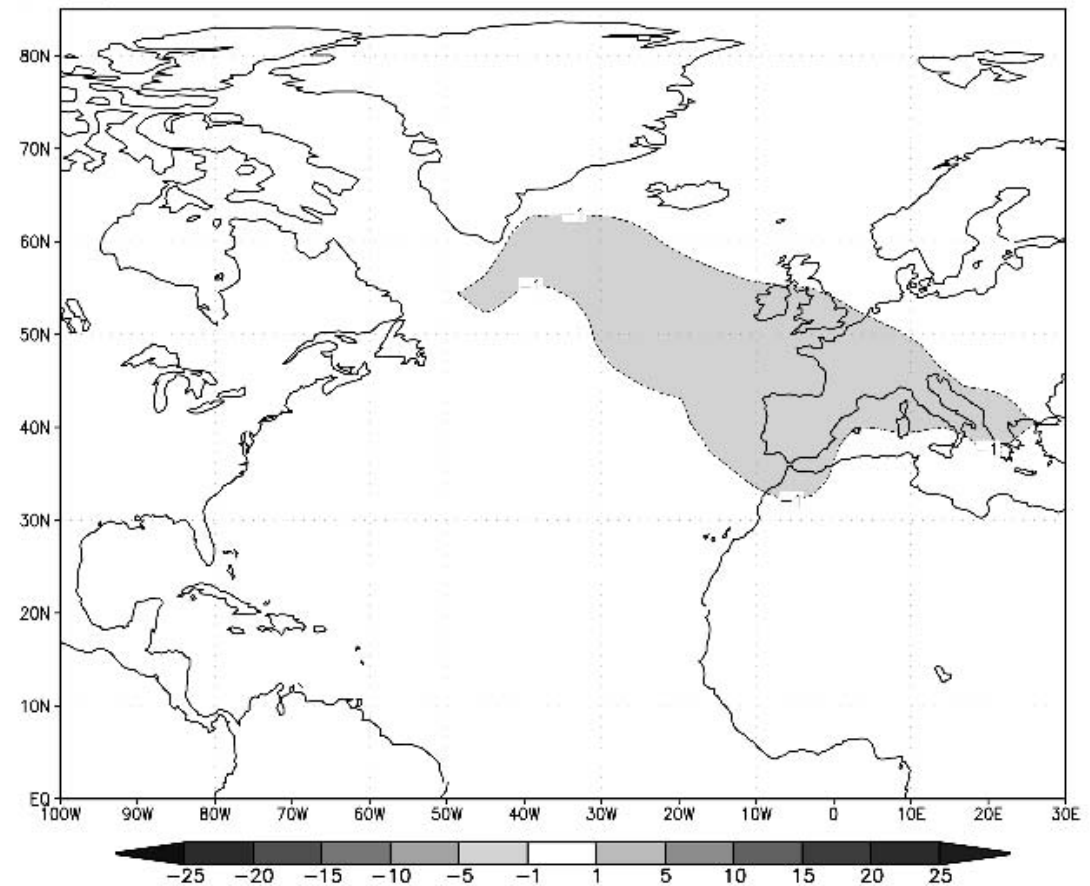

b) regr. coeff., stddev $500 \mathrm{hPa}$ GPH, ECHAM5-MLO (10E-1)

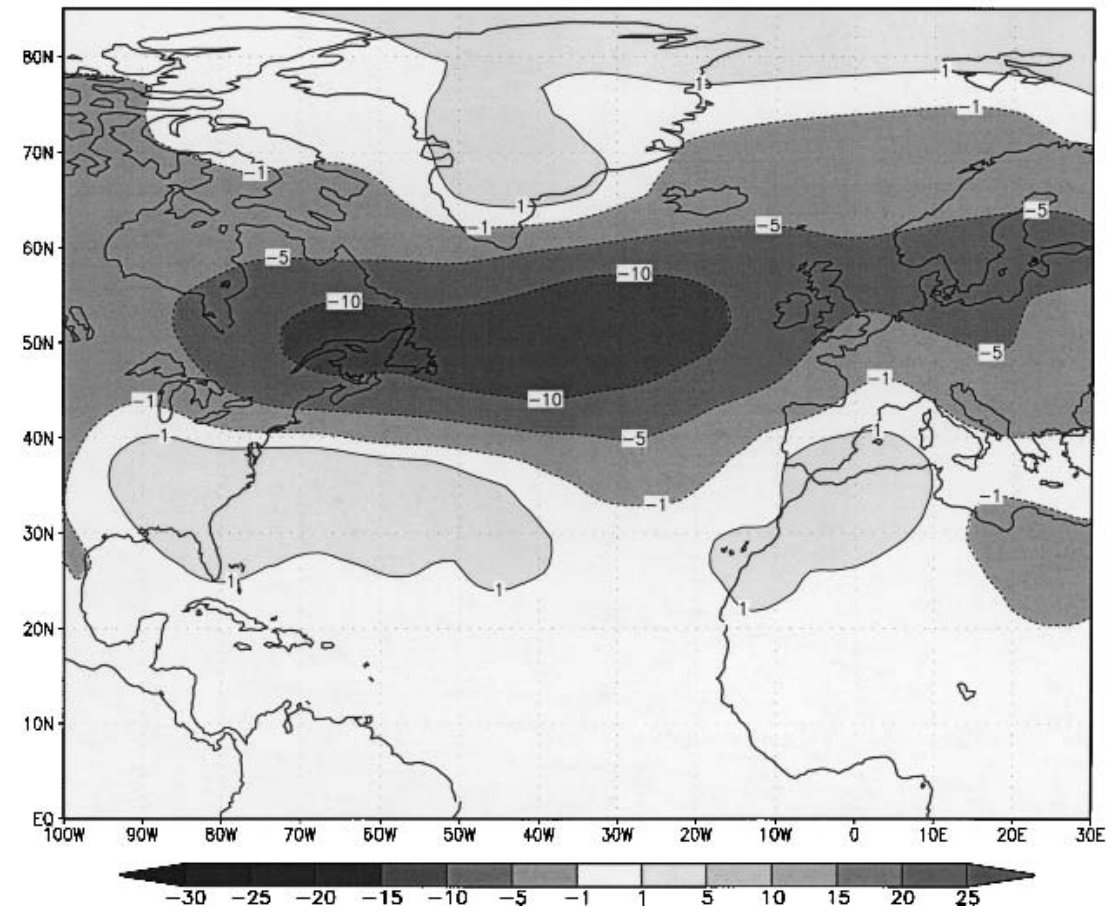

FIG. 8. Same as in Fig. 7, but for maps of linear regression coefficients of the bandpassfiltered (2.5-6 days) winter (DJF) geopotential height variability at the 500-hPa level with respect to the SST indices shown in Fig. 2.

associated SLP anomaly patterns in both runs are indeed response patterns and determined by the changes in the underlying SST. An alternative extreme view is, on the other hand, that there is no atmospheric re- sponse at all in the mixed layer integration, so that only a one-way interaction such that the atmosphere drives the tripolar SST anomaly pattern exists. A relatively short uncoupled experiment with our AGCM and mul- 
a) regr. coeff., eddy heat flux, ECHAM5-OGCM (5*10E-2)

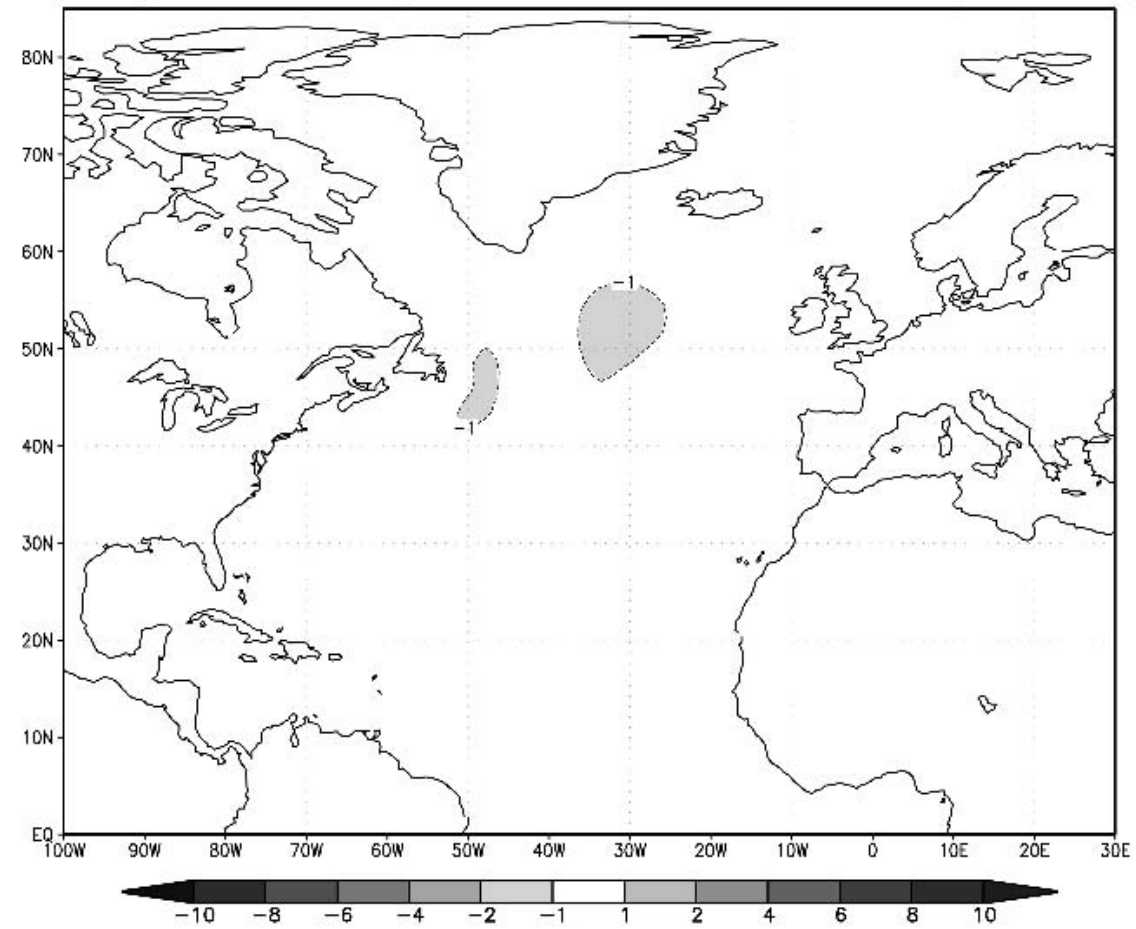

b) regr. coeff., eddy heat flux, ECHAM5-MLO $(5 * 10 \mathrm{E}-2)$

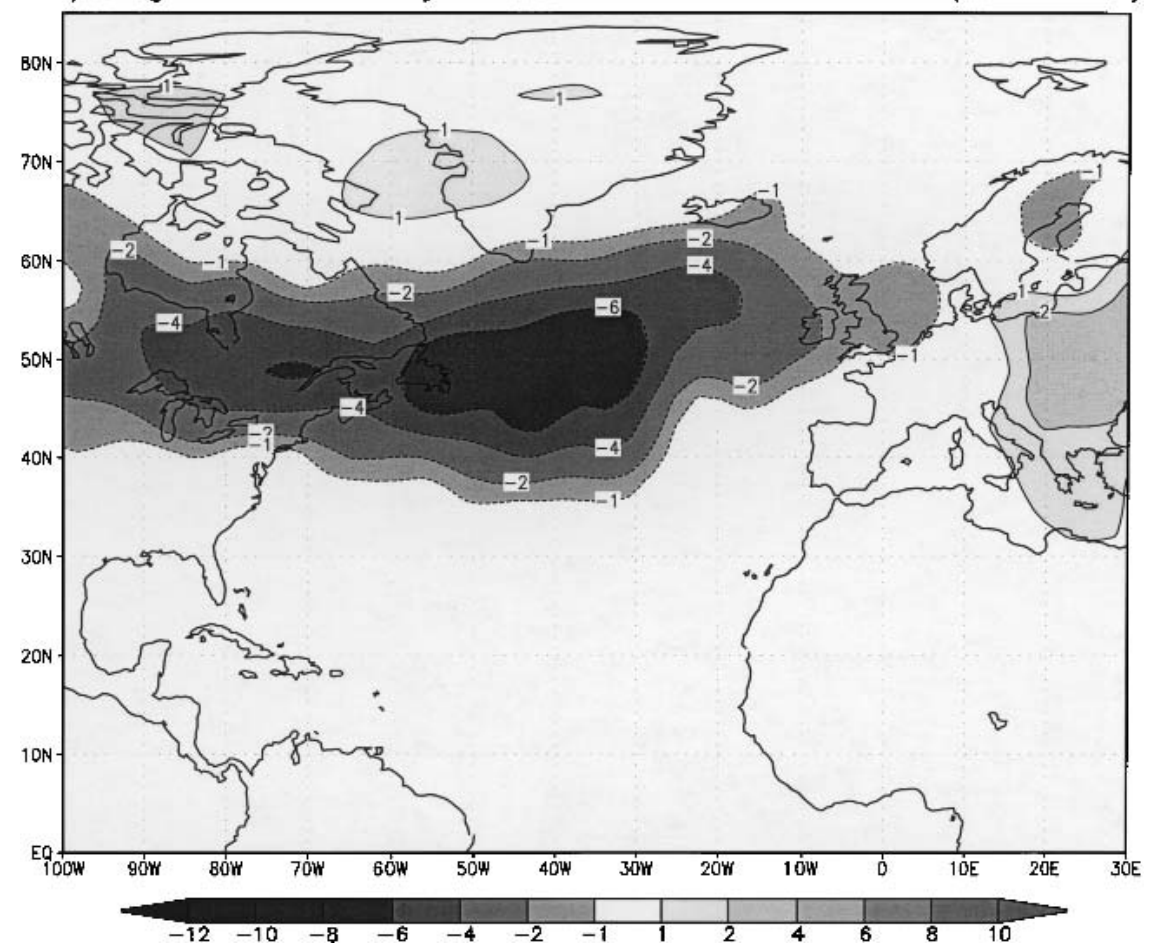

FIG. 9. Same as in Fig. 8, but for meridional eddy heat flux. 
ticentury integrations with a different model version, however, suggest that the SLP anomaly pattern associated with the decadal SST anomalies in the coupled run with the mixed layer model, the NAO, is not only a forcing, but also a response pattern. Thus, we believe that the atmospheric patterns associated with the decadal-scale SST anomalies in the two coupled runs are indeed response patterns.

The flatter decadal SLP anomaly pattern in the run with the dynamical ocean model, resembling the EAP, however, can be explained only if two-sided air-sea interactions are invoked, since it does not occur as one of the leading modes in the mixed layer integration. Latif et al. (2004) show that the monopolar SST anomaly pattern is driven by ocean dynamics, specifically by variations in the THC and the associated changes in the poleward heat transport, and that the surface heat flux acts as a negative feedback. Since the EAP-like pattern is not one of the leading modes in the coupled run with the mixed layer ocean, its climatological significance in the coupled run with the dynamical ocean model must be introduced through the changes in the SST.

We note that the NAO is the leading mode in both coupled integrations at interannual time scales. This result was obtained from EOF analysis of annual SLP anomalies simulated in the two coupled runs (not shown). Furthermore, the associated SST anomaly (SSTA) patterns (the tripolar SSTA pattern) are identical in the two coupled runs at these interannual time scales. Thus, it seems likely that the structure of the air-sea interactions over the North Atlantic is mostly affected by the underlying SST at decadal or longer time scales. This suggests that the midlatitudinal atmosphere is sensitive to changes in the underlying SST primarily at decadal time scales. We find that the atmospheric response pattern at decadal time scales is not necessarily the variability pattern that prevails at interannual time scales and that may have forced the variations in the ocean by changing convection in the first place. Thus, the decadal variations in the THC, for instance, may be driven by variations of the NAO, but the atmospheric response to the subsequent decadal-scale SST changes may project onto another pattern, depending on the prevailing SST anomaly pattern. This seems to happen in the run with active ocean dynamics, in which the response pattern at decadal time scales resembles the EAP.

Acknowledgments. We thank Dr. E. Roeckner for providing the ECHAM5 and the mixed layer models and Mrs. M. Esch for assistance in running them. We thank Dr. D. Dommenget for fruitful discussions and Dr. U. Merkel for providing the eddy statistics programs. Dr. N. Keenlyside made useful comments on an earlier version of the manuscript. The help of Drs. J. Jungclaus and M. Botzet in providing the model data is greatly appreciated. W. Park is supported by the post- doctoral fellowship program of the Korea Science and Engineering Foundation (KOSEF). This work was supported by the DEKLIM Project of BMBF and by the Sonderforschungsprogramm "Dynamik der thermohalinen Zirkulation" of DFG. The coupled model integrations were performed at the Deutsches Klimarechenzentrum (DKRZ).

\section{REFERENCES}

Bjerknes, J., 1964: Atlantic air-sea interaction. Advances in Geophysics, Vol. 10, Academic Press, 1-82.

Bretherton, C. S., M. Widmann, V. P. Dymnikov, J. M. Wallace, and I. Blade, 1999: The effective number of spatial degrees of freedom in a time-varying field. J. Climate, 12, 1990-2009.

Delworth, T. L., and M. E. Mann, 2000: Observed and simulated multidecadal variability in the Northern Hemisphere. Climate Dyn., 16, 661-676.

_ - S. Manabe, and R. J. Stouffer, 1993: Interdecadal variations of the thermohaline circulation in a coupled oceanatmosphere model. J. Climate, 6, 1993-2011.

— — - and —_, 1997: Multidecadal climate variability in the Greenland Sea and surrounding regions: A coupled model simulation. Geophys. Res. Lett., 24, 257-260.

Deser, C., and M. L. Blackmon, 1993: Surface climate variations over the North Atlantic during winter: 1900-1989. J. Climate, 6, 1743-1753.

Dommenget, D., and M. Latif, 2002: Analysis of observed and simulated SST spectra in midlatitudes. Climate Dyn., 19, $277-$ 288

Folland, C. K., D. E. Parker, and F. E. Kates, 1984: Worldwide marine temperature fluctuations 1856-1981. Nature, 310, 670-673.

_ , T. N. Palmer, and D. E. Parker, 1986: Sahel rainfall and worldwide sea temperatures, 1901-85. Nature, 320, 602-607.

Frankignoul, C., 1985: Sea surface temperature anomalies, planetary waves and air-sea feedback in midlatitutdes. Rev. Geophys., 23, 357-390.

Hasselmann, K., 1976: Stochastic climate models. Part I: Theory. Tellus, 28, 473-485.

Kushnir, Y., 1994: Interdecadal variations in North Atlantic sea surface temperature and atmospheric conditions. J. Climate, 7, 141-157.

Latif, M., 1998: Dynamics of interdecadal variability in coupled ocean-atmosphere models. J. Climate, 11, 602-624.

— dicting multidecadal-scale changes in the North Atlantic thermohaline circulation with sea surface temperature. J. Climate, 17, 1605-1614.

Lindzen, R. S., and S. Nigam, 1987: On the role of sea surface temperature gradients in forcing low-level winds and convergence in the Tropics. J. Atmos. Sci., 44, 2418-2436.

Manabe, S., and R. J. Stouffer, 1996: Low-frequency variability of surface air temperature in a 1000-year integration of a coupled atmosphere-ocean-land surface model. J. Climate, 9, 376-393.

Marsland, S. J., H. Haak, J. Jungclaus, M. Latif, and F. Röske, 2003: The Max-Planck-Institute global ocean/sea ice model with orthogonal curvilinear coordinates. Ocean Modell., 5, 91-127.

Palmer, T. N., 1993a: A nonlinear dynamical perspective on climate change. Weather, 48, 314-326.

- 1993b: Extended-range atmospheric prediction and the Lorenz model. Bull. Amer. Meteor. Soc., 74, 49-65. , and Z. Sun, 1985: A modelling and observational study of 
the relationship between sea surface temperature in the north-west Atlantic and the atmospheric general circulation. Quart. J. Roy. Meteor. Soc., 111, 947-975.

Pohlmann, H., M. Botzet, M. Latif, A. Roesch, M. Wild, and P. Tschuk, 2004: Estimating the decadal predictability of a coupled AOGCM. J. Climate, 17, 4463-4472.

Roeckner, E., and Coauthors, 2003: The atmospheric general circulation model ECHAM 5. Part I: Model description. Rep. 349, Max-Planck-Institute for Meteorology, 127 pp. [Available from Max Planck Institute for Meteorology, Bundesstr., 53, D-20146 Hamburg, Germany.]
Timmermann, A., M. Latif, R. Voss, and A. Grötzner, 1998 Northern Hemisphere interdecadal variability: A coupled air-sea mode. J. Climate, 11, 1906-1931.

Visbeck, M., H. Cullen, G. Krahmann, and N. Naik, 1998: An ocean model's response to North Atlantic Oscillation like wind forcing. Geophys. Res. Lett., 25, 4521-4524.

Wallace, J. M., and D. S. Gutzler, 1981: Teleconnections in the geopotential height field during the Northern Hemisphere winter. Mon. Wea. Rev., 109, 784-812.

Winton, M., 2003: On the climatic impact of ocean circulation. $J$. Climate, 16, 2875-2889. 